\title{
Child Protection Training in Sport- related Degrees and Initial Teacher Training for Physical Education: An Audit
}

This article reports on an online survey of child protection training for students on sport-related and Initial Teacher Training Physical Education degrees, and on the views of recently graduated teachers of the usefulness of such training in their everyday work. The results indicate that child protection training is provided in most courses but in varying amounts. Respondents to the survey reported positively, in the main, about the effects of new requirements for teacher training (Every Child Matters: Change for Children, Department for Education and Skills, 2004). Reasons given for not including child protection in courses were: lack of time; the perceived vocational nature of the topic; lack of fit with course aims and objectives; lack of relevance; and the research rather than professional orientation of the course. Recently graduated teachers' views on their pre-service child protection training differed from the claims made about this in the survey. In particular, they raised concerns about their lack of preparation for dealing with potential child protection situations. The article concludes that child protection training within sport-related degrees is deficient in both consistency of delivery and in content, and that, in addition to preparing students to recognise signs and indicators of abuse, curricula should also address undergraduates' confidence and skills for responding to abuse in their everyday professional practice. Copyright (c 2008 John Wiley \& Sons, Ltd.

KEY WORDS: child protection; safeguarding; training; education; abuse

$\mathbf{T}$ he Children Act (1989) emphasised the development and monitoring of child protection $(\mathrm{CP})$ procedures within institutions, including schools, but did not make any reference to requirements for CP training within Initial Teacher Training (ITT). Maher (1987)

* Correspondence to: Professor Celia Brackenridge, School of Sport and Education, Heinz Wolff Building, Brunel University, Kingston Lane, Uxbridge, Middlesex UB8 3PH, UK. E-mail: celia.brackenridge@brunel.ac.uk

Claire Rossato Celia Brackenridge* Brunel University, UK 
proposed an extension of professional training in CP to include schools but this was only for those already in a teaching position, and thus excluded trainee teachers. It has been argued consistently that the impact of CP services appears, at the documented level, to be minimal (Gibbons et al., 1995). Cawson et al.'s (2000) study of child maltreatment reports that school-age children are a vulnerable age group. Teachers are frequently the first authority figures with any sort of relationship with abused children and can potentially therefore play a role in protecting or helping a child who they identify as at risk or who makes a disclosure to them.

As research by Baginsky and Hodgkinson (1999) found, the coverage of CP in teacher training in England and Wales is best described as patchy. ITT within higher education departments preparing student teachers lacks consistency in the amount of time spent on researching and learning about $\mathrm{CP}$ needs within education. In relation to child care, Reder and Duncan (2004), supported by Devaney (2004), argue that training is the cornerstone to improving practice and to preventing both system and practice failures, failures that might also apply to social care, education or youth sport.

Sport contributes to the welfare of young children (Mason, 1995) and is now a key vehicle for the delivery of a wide range of government policy targets related to health, civic pride and social inclusion (Coalter, 2007). It is therefore important to have sound $\mathrm{CP}$ procedures in place in all sport environments, whether within or beyond the school (Brackenridge, 1994, 2001; Brackenridge and Kirby, 1997). Schemes for youth sport are based on the assumption that sport contributes to the wellbeing of children (Mason, 1995). However, it is arguable whether all sport environments have fully embedded safeguarding in their work.

Such was the concern about child abuse in sport by the end of the 1990s that, in 2001, a Child Protection in Sport Unit (CPSU) was established within the National Society for Prevention of Cruelty to Children (NSPCC) (Boocock, 2002). Its work has focused largely on youth sport and sport services delivered through National Governing Bodies of sport (NGBs) and local authorities. The major provider of youth sport schemes, the Youth Sport Trust, draws heavily on the expertise of the CPSU in both its school-based and out-of-school welfare work. One of the main mechanisms for increasing children's levels of participation in sport and physical activity is the physical education (PE), School Sport and Club Links (http://www.sportengland.org/pesscl.htm), known as the PESSCL strategy (Sport England, 2004). A national development officer post within the CPSU supports safeguarding within PESSCL. ${ }^{1}$

${ }^{1}$ Safeguarding is the wider concept that has replaced CP in England and Wales. However, at the time that the graduates in this study went through their degree courses "child protection' was still the most commonly used and understood term. It is therefore adopted here. 
Since the formation of the CPSU, the NGBs in England have come under increased scrutiny from the government. For example, National Standards for Safeguarding and Protecting Children in Sport were introduced in 2003 as a criterion of grant aid (CPSU, 2003). According to the CPSU (2006a), those directly or indirectly involved with children's sport have a responsibility to comply with recognised safeguarding practices. The broadest strategic advice for CP in sport is provided in the CPSU's Strategy for Safeguarding Children and Young People in Sport 2006-2012 (2006b). One key outcome of this is to develop and implement a national strategy for safeguarding skills and knowledge which has been pursued by a multi-agency steering group since 2006 (CPSU, 2007).

The inclusion of CP within sport policy creates a quality of service to which anyone who takes part in sport should be entitled (Brackenridge, 2002). Many funded sport bodies, however, are finding it difficult to come to terms with the requirements for dealing with CP and abuse of trust (Brackenridge, 2004; Hartill and Prescott, 2007; Home Office, 1999, 2000) and both County Sports Partnerships and NGBs have struggled to disseminate the CPSU advice in the education sector (G. Joyce, personal communication, 17 April 2008). In addition, criminal record vetting remains somewhat controversial, both within and beyond sport, and research has concluded that the structure of sport is not necessarily conducive to the implementation of CP (Collins, 2006; Tomlinson and Yorganci, 1997).

The five key outcomes for children set out in Every Child Matters: Change for Children (ECM) (DfES (Department for Education and Science), 2004) match very closely the CPSU's National Safeguarding Standards (CPSU, 2003) and the Training and Development Agency's (TDA) Professional Standards for Teachers (TDA, 2007) which come into practice in September 2008. The latter state (Section P6) that teachers should have sufficient depth of knowledge and experience to be able to give advice on the development and wellbeing of children and young adults. If the standards were met then trainee teachers should be capable of dealing with and reporting safeguarding concerns in any context.

In 1999, Baginsky and Hodgkinson argued that whether teachers received in-service training at all, or early enough for appropriate intervention, remained a matter of chance. Although $\mathrm{CP}$ is now given priority under the new safeguarding arrangements, educators could argue that mandatory requirements are still not sufficient for the school setting. Certainly, the CP training offered in sport-related degrees is, as yet, un-researched. The purpose of this study therefore was to establish baseline data for the type, level, extent and duration of the CP training offered to students on such degrees. The study also explored views of recent graduates working within youth sport and PE of their awareness, confidence and competence in relation to $\mathrm{CP}$ issues. 


\section{Research Design}

An explanatory letter and an online survey about CP training and awareness were emailed to 126 course leaders at 55 higher education institutions providing PE ITT and sport-related degrees, located via the British Association of Sport and Exercise Science web-based course finder and the Graduate Teacher Training Registry within the UK, excluding Scotland (which has different law in this area). Course leaders were chosen as they have responsibility for managing curriculum relevance and content. The sport-related degrees included Bachelor of Science (BSc), Bachelor of Arts (BA), Master of Science (MSc) and Master of Arts (MA) courses. ITT courses included the Post Graduate Certificate in Education (PGCE) within PE or PE degrees leading to Qualified Teacher Status within secondary education.

Ethical approval was given by the relevant ethics committee of the authors' university. The questionnaire guaranteed anonymity and confidentiality. Respondents gave informed consent by filling out and returning the questionnaire. The survey was adapted from that used by Baginsky and Hodgkinson (1999) to explore in-house CP training within PGCE courses (pre-dating the introduction of 'safeguarding'): it comprised mainly closed items but also offered a section for reflective comments. Most returns were received within four weeks after which reminders were sent to non-respondents. Returns received beyond six weeks were excluded from the analysis. The return rate was 36 per cent $(n=20)$ of the 55 institutions and 33 per cent $(n=42)$ of the 126 courses, which is deemed acceptable for postal surveys. Altogether, 76 per cent $(n=32)$ of institutional returns were from $\mathrm{BSc} / \mathrm{BA}$ undergraduate courses related to sport science, 17 per cent $(n=7)$ from PGCE courses related to sport and seven per cent $(n=3)$ from MSc/MA sport-related courses.

Fifty-two per cent $(n=22)$ of all responding surveys were completed by course leaders/coordinators, 22 per cent $(n=9)$ by a member of the teaching team, 12 per cent $(n=5)$ by people describing themselves as 'tutors' and 14 per cent $(n=6)$ by heads of department. What follows is therefore an analysis of course provision as seen by academic staff and not what is actually experienced by students.

In conjunction with the survey, two groups, each comprising two recent graduate sports/PE teachers (who had graduated within the last four years), were interviewed $(n=4)$. Pilot testing of the interview schedules was carried out beforehand. Written, informed consent was gained from all participants before the interviews and the interviewer provided a list of counselling numbers and support information in case participants needed this. Before the interviews, the participants were asked to fill out a short form detailing their backgrounds. They were asked what type of training they had received with respect to $\mathrm{CP}$ within their higher education courses. 
As ice breakers, interviewees were given scenarios to discuss at the start of the interviews, including examples of neglect, physical, sexual and emotional abuse as identified by the NSPCC (Cawson et al., 2000). This was done in order to acclimatise respondents to relevant topics that might arise from the subject matter. After the scenarios were presented, open-ended questions were asked in order to promote discussion. These questions explored what $\mathrm{CP}$ training they had received, its adequacy, how it was presented, whether they were satisfied and what areas they felt could have been improved.

\section{Findings and Discussion}

\section{Coverage and Time Allocation}

Of the respondents to the online survey, 28 course leaders (67\%) reported that they included $\mathrm{CP}$ training within their respective course syllabi and all of these reported that this coverage was compulsory. All respondents from PGCE courses related to sport $(n=7)$ included CP, whereas $28(80 \%)$ of the 35 respondents from sports-related degrees (including one oriented towards PE) did so.

Of the 35 sports-related degrees in the sample group, of which only one was PE orientated, 28 included CP. A total of 14 courses, of which three were $\mathrm{MSc} / \mathrm{MA}$ and 11 were $\mathrm{BSc} / \mathrm{BA}$, offered no coverage at all. Of these 14 , six respondents did not provide reasons for not including $\mathrm{CP}$ within their syllabi. Three explained that coach education was not included in their course and thus CP was not deemed necessary. One respondent added that they did not have time to fit $\mathrm{CP}$ into the course: another wrote that it did not fit with the aims and objectives of the course and that students interested in the area were directed towards the Sports Coach UK (SCUK) workshop on this subject. A further reason given for excluding $\mathrm{CP}$ was that the course focused only on adults as examples within sport. Lastly, one respondent replied that their course was an academic, research-focused MSc and excluded $\mathrm{CP}$ because it was regarded as a 'vocational topic'. This reflects a somewhat narrow conception of the relevance of CP. However, the respondents did stress that extra training in the area should be a key element of a professional practitioner qualification programme.

Respondents were also asked about future plans for including CP in their courses. Eight replied that they had no plans, three were unsure, one because of time difficulties, and two said yes, one of whom reported that they had already made provision to include $\mathrm{CP}$ in the course the next academic year. Ten respondents were able to identify who to approach if they needed further support and information on this theme but four reported that they would not know who to approach. 


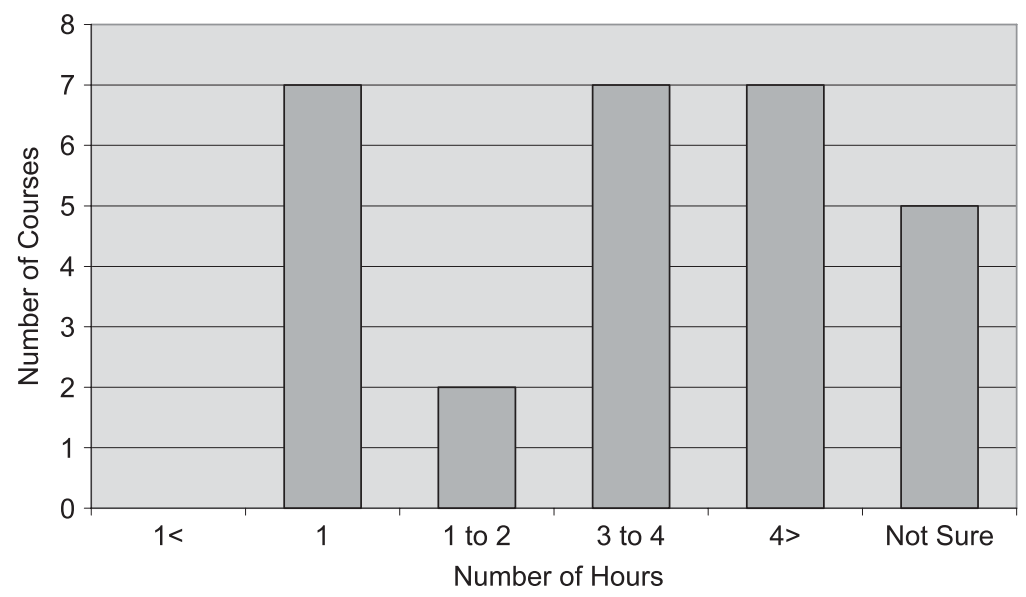

Figure 1. Frequency and duration of the child protection training element within higher education sport/physical education courses $(n=28)$

Respondents who included CP in their courses were asked to report the length of time spent on this element. The results are summarised in Figure 1. All respondents reported offering one or more hours of training in their courses.

One degree course offered up to 30 hours of training. Four respondents were unsure about how much time was allocated. Most respondents $(64 \%, \mathrm{n}=18)$ included $\mathrm{CP}$ within the first year of the degree and 21 per cent $(n=6)$ included coverage of CP within the third year of the course, which would suggest that it is not revisited in most degree courses after the first year. Similarly, 21 per cent $(n=6)$ included coverage in the second year: of these, 18 per cent $(n=5)$ were PGCE courses and all covered CP (this adds up to more than $100 \%$ since some courses revisit CP education throughout the course). From these findings it is clear that, for whatever reason, most of the courses for which returns were made have included CP training.

\section{Course Content and Teaching Methods}

Data about the content of the CP input to courses are summarised in Table 1. Information about $\mathrm{CP}$ within school $\mathrm{PE}$ and school sport was included in 86 per cent of courses $(n=24)$. Both case studies of child abuse in PE and sport and how to detect children at risk in these contexts were included in 79 per cent of courses $(n=22)$ but seven per cent $(n=2)$ replied that they were unsure what was taught under this coverage. From their replies, it seems that courses adhere broadly to the CPSU guidance (2006a) described above.

Data on the methods deployed for the delivery of the CP course content are shown in Table 2. In most courses the content was delivered via lectures $(86 \%, n=24)$ and workshops $(54 \%, n=15)$, with 21 per cent $(n=6)$ of respondents unsure how the information 
Table 1. Coverage of different child protection (CP) themes within higher education sport/ physical education courses

Courses offering

Content $(\mathrm{N}=28)$

coverage $\mathrm{n}(\%)$

Procedures for dealing with suspected abuse in a PE/sport context $23(82)$

$\begin{array}{ll}\text { Detection of children at risk in a PE/sport context } & 22(79)\end{array}$

Agencies involved in CP cases in PE/sport context 23 (82)

Incidence of CP cases in schools within a PE/sport context 24 (86)

Incidence of CP cases in society outside a PE/sport context

Discussion of case studies 22 (79)

$\begin{array}{ll}\text { Other issues } & 2(7)\end{array}$

Table 2. Methods used to deliver child protection training within higher education sport/ physical education courses

\begin{tabular}{lc}
\hline Methods $(\mathrm{N}=28)$ & Courses using methods $\mathrm{n}(\%)$ \\
\hline Lectures & $24(86)$ \\
Discussion groups & $13(46)$ \\
Seminars & $12(43)$ \\
Workshops & $15(54)$ \\
Distance learning materials & $9(32)$ \\
Not sure & $6(21)$ \\
Other & $6(21)$
\end{tabular}

was delivered. This would suggest that, although the course covered $\mathrm{CP}$, the responding tutors were not exactly sure how and what they were supposed to be teaching.

The survey also asked who taught the $\mathrm{CP}$ element. The results are summarised in Figure 2. Non-specialists were used in 52 per cent $(n=14)$ of cases, specialists in 46 per cent $(n=13)$ of cases, school teachers in 14 per cent $(n=4)$ and visiting speakers in 25 per cent $(\mathrm{n}=7)$. (This does not add up to 100 per cent as some institutions use more than one method of delivery.) These results suggest that there is an absence of knowledge within core staff, supporting the conclusions of Carpenter (2005) and Malkin et al. (2000) that CP within the education system is lacking.

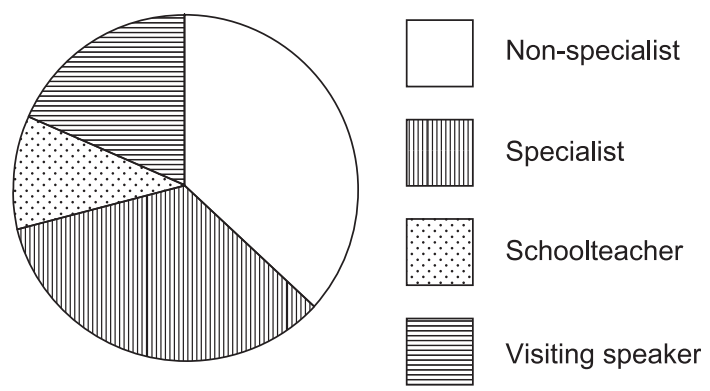

Figure 2. Percentage distribution of the roles of tutors delivering child protection $(\mathrm{CP})$ training within higher education sport/physical education courses $(n=38)$. (The $n$ sums to more than the total respondents as some institutions had multiple delivery methods of $\mathrm{CP}$ training.) 
Table 3. Tutors' perceived impact of Every Child Matters and new Initial Teacher Training guidelines for child protection training within higher education sport/physical education courses

Perceived impact $(\mathrm{N}=28)$

Responses n (\%)

No effect at all

\section{The Impact of Recent Teacher Training Guidance}

Respondents were asked to assess the likely longer term effects on their course provision of the recent mandatory regulations for ITT - the 2004 Framework for ECM (see Table 3). None of the replies projected decreases in coverage of $\mathrm{CP}$ and 26 per cent $(n=11)$ reported no projected effects at all. The majority noted that coverage was likely to increase. Other reasons for their lack of awareness of the guidance was given by 14 per cent $(n=6)$. One respondent suggested that CP was not relevant for a nonteaching-oriented course, again revealing a narrow interpretation of the issue. Two reported that the levels of professional responsibility and accountability required because of ECM (DfES, 2004) were likely to result in an increase in complexity and sophistication of content rather than an increase in the volume of coverage per se. Awareness of ECM appeared to be reasonably good, boding well for the introduction of the new TDA standards in 2008.

\section{Reflective Comments}

Respondents were invited to add any additional comments they wished to make about the coverage of CP issues in their courses. Only four respondents did so. One wrote of the ECM documentation: 'Like most tutors I suspect that the advent of the ECM will raise the profile of child protection.' Another noted: 'I would be horrified if ITE [Initial Teacher Education] courses that you survey do not cover this area, as a key part of their work.' Overall, whilst it is reassuring to note that ECM is recognised as important by tutors, it is less clear whether it is being applied systematically within their courses. The findings here thus support Baginsky and Hodgkinson's (1999) description of CP education coverage as 'patchy'.

\section{Teacher Interviews}

Verbatim transcripts from the group interviews were analysed using hierarchical content analysis, a process that identifies raw data 
themes, properties and dimensions (Miles and Huberman, 1994). All of the recent graduate teachers reported having received $\mathrm{CP}$ education within their PGCE or other externally run courses. None had received training from previous degrees other than the PGCE course. Both Maher (1987) and the Children Act (1989) pointed out that ITT did not include any training requirements for $\mathrm{CP}$ in the late 1980s so the results here reflect a considerable improvement. The group interview participants reported however that, although their higher education training equipped them to identify the signs and indicators of abuse, insufficient attention had been paid to the practicalities of dealing with and reporting CP concerns.

The teachers also expressed anxiety about allegations and how to avoid them. For example, when discussing the topic of comforting an injured pupil a teacher said:

'I mean, as long as you have your body position open then that reduces the chance of someone accusing you or seeing something that's not happening as it's in full view.'

One teacher was worried about the effects on peer teachers who might be involved in reporting them for abuse and another suggested that the possibility of unfounded accusations impacted on the work of designated $\mathrm{CP} /$ Welfare Officers:

'I have dealt with Child Welfare Officers to rectify situations and it has not worked as they are worried to say or suggest interventions which could improve the situation.'

Commenting on one scenario, another teacher said:

'I have put myself in a situation which is volatile and I could get myself in trouble ... there is not a lot of education on that side of the scenario.'

The teachers reported feeling able to deal with minor situations but not with major ones. They agreed, however, that it was not their job to deal with situations but simply to identify what was going on and to make appropriate referrals. One teacher said:

\footnotetext{
'At least in a school there is a student manager or Head of Welfare expressing the problem. From that way it's a lot easier because you put it onto people who know what to do.'
}

For these teachers, their CP training appeared to have ignored mechanisms for reporting and dealing with abuse-related situations, resulting in a lack of knowledge and confidence about this.

The teachers were also asked about their pre-service and inservice CP training experiences. Regarding PGCE (pre-service) training, one reported not having received any, two had done some 
(of one-two hours' duration) and one was unsure. One had received no further training in the two years since their degree, two had been on a workshop run by the Football Association and another reported completing a number of CP training sessions at previous schools:

'At my old place of work we did three two hour child protection workshops, and that's all I've done. That was only for Ofsted because we needed to do it and the college wanted to show that they were up to date.'

This implies that the teachers were unaware of the ECM (DfES, 2004) framework, which is concerning. The participants were also asked how satisfied they were with the training that they had received. One replied that, 'deep down' if a serious issue came about they did not think that they could handle it. Another felt that it was not their job to be an expert in CP and, if it were, then they would have received more training, which could reflect a message from their degree preparation. They argued that it was better to refer to someone with more knowledge of the issue than they had. It is certainly the case in SCUK workshops that coaches are told they have a responsibility to refer (i.e. to act, rather than to make judgments about possible abuse). The new ECM guidance also stresses that safeguarding is everyone's responsibility but clearly some teachers are still uncertain about this. Overall then, despite their important potential role in relation to $\mathrm{CP}$, it would seem that these particular teachers have only a minimum level of knowledge on the subject, and that their knowledge and confidence are inadequate for their professional responsibilities (Baginsky and Hodgkinson, 1999; Gibbons et al., 1995).

\section{Limitations}

The data here have a number of weaknesses. First, the non-response to the survey could mask a higher level and/or greater diversity of training activity than was reported. The fact that the data were requested for a masters degree dissertation (Rossato, 2007) might have made course leaders more reluctant to reply than had the request emanated from, for example, the NSPCC or the TDA. Further, the validity of the data could be compromised if the responding tutors were not those responsible for actual course delivery. The group interviews were drawn from a very small sample and should be regarded as no more than a pilot for further in-depth work. In particular, the professional experiences of sport development officers and sport coaches were not gathered: they should be included in any future study. Finally, the timing of the study may have confounded the apparent inadequacies in training provision, falling as it did just after the introduction of ECM and 
just before the introduction of the new TDA guidelines: this meant that higher education had had relatively little time to adjust to these initiatives.

\section{Conclusions}

It is encouraging to note that the government is working on improving $\mathrm{CP}$ and safeguarding training (TDA, 2007). However, the findings of this study suggest that there is still much more to do. Many of the concerns expressed in previous studies, such as those about unfounded allegations, have been reinforced here in the context of the professional preparation of youth sport workers and PE teachers. CP training in sport-related degrees and ITT PE courses is, at best, unbalanced and, with specific regard to reporting procedures and practices, inadequate. There thus appears to be a training gap within CP training for professionals who will enter the sport and teaching industries and take forward the youth sport agenda.

Within the sports sector there is widespread concern about the disparity in knowledge and practices between well-informed coaches and volunteers and those working in partnerships with them from education. The sport sector had previously held a presumption that this expertise would lie within the teaching profession and yet, in many ways, it is the sport sector that is ahead of PE in this area. Finally, there is a clear need for more up-to-date research in order to examine how the new TDA and ECM guidelines are affecting PE teachers' and sport workers' everyday practice in dealing with child abuse situations.

\section{Acknowledgement}

We are indebted to Gill Joyce of the NSPCC CPSU for her many invaluable observations and comments on this article.

\section{References}

Baginsky M, Hodgkinson K. 1999. Child protection training in initial teacher training: A survey of provision in institutions of higher education. Educational Research Volume 41: 173-181.

Boocock S. 2002. The Child Protection in Sport Unit. Journal of Sexual Aggression 8(2): 99-106.

Brackenridge CH. 1994. Fair play or fair game: Child sexual abuse in sport organisations. International Review for the Sociology of Sport 29(3): 287299.

Brackenridge CH. 2001. Spoilsports: Understanding and Preventing Sexual Exploitation in Sports. Routledge: London. 
Brackenridge CH. 2002. ' $\ldots$ so what?' Attitudes of the voluntary sector towards child protection in sports clubs. Managing Leisure 7: 103-123.

Brackenridge CH. 2004. Burden or benefit? The impact of sportscotland's Child Protection Programme with Governing Bodies of Sport. Research Report 94, Edinburgh: sportscotland.

Brackenridge CH, Kirby S. 1997. Playing safe: Assessing the risk of sexual abuse to elite child athletes. International Review for the Sociology of Sport 32(4): 407-418.

Carpenter J. 2005. Evaluating Outcome in Social Work Education', Scottish Institute for Excellence in Social Work Education/Social care Institute for Excellence. Discussion Paper No. 1. Dundee: SIESWE/SCIE.

Cawson P, Wattam C, Brooker S, Kelly G. 2000. Child Maltreatment in the UK: A study of the prevalence of child abuse and neglect. London: National Society for Prevention of Cruelty to Children.

CPSU (Child Protection in Sport Unit). 2003. National Standards for Safeguarding and Protecting Children in Sport. Leicester: National Society for Prevention of Cruelty to Children.

CPSU (Child Protection in Sport Unit). 2006a. Protocol for Safeguarding Children. Available: http://www.thecpsu.org.uk/Documents/PESSCL\%20NSS\% 20Strategy\%20Protocol\%20Final\%20June06.rtf [31 March 2008].

CPSU (Child Protection in Sport Unit). 2006b. Strategy for Safeguarding Children and Young People in Sport 2006-2012. Leicester: National Society for Prevention of Cruelty to Children.

CPSU (Child Protection in Sport Unit). 2007. Guidance document: Roles, Skills, Knowledge and Competencies for Safeguarding Children in the Sports Sector. Leicester: National Society for Prevention of Cruelty to Children.

Children Act. 1989. (C.41) Office of Public Sector Information: London. Available: http://www.opsi.gov.uk/acts/acts1989/Ukpga_19890041_en_1.htm [5 January, 2007].

Coalter F. 2007. A Wider Role for Sport: Who's keeping the Score? London: Routledge.

Collins T. 2006. Child protection in high performance gymnastics. Unpublished paper to a symposium on Training the Elite Child Athlete, hosted by Brunel University and the National Society for Prevention of Cruelty to Children, London, 4 May.

Devaney J. 2004. Relating outcomes and objectives in Child Protection. Child and Family Social Work 9: 27-38.

DfES (Department for Education and Skills). 2004. Every Child Matters: Change for Children. $1^{\text {st }}$ ed. DfES: London. Available: http://www. everychildmatters. gov.uk/_files/F9E3F941DC8D4580539EE4C743E9371D.pdf [8 August 2007].

Gibbons J, Conroy S, Bell C, Gordon D. 1995. Development after Physical Abuse in Early Childhood. A follow up study on children on child protection registers. HMSO: London.

Hartill M, Prescott P. 2007. Safeguarding and Child Protection Policy in British Rugby League. Child Abuse Review 16(4): 237-251. DOI: 10.1002/car.990

Home Office. 1999. Caring for Young People and the Vulnerable: Guidance for Preventing Abuse of Trust. $1^{\text {st }}$ ed. London: Home Office. Available: http:// www.ccpas.co.uk/Documents/Abuse \%20of\%20Trust.pdf [1 January 2007].

Home Office. 2000. Sexual Offences (Amendment) Act. Chapter 4. $1^{\text {st }}$ ed. Office of Public Sector Information: London. Available: http://www.opsi.gov.uk/ acts/acts2000/20000044.htm [8 August 2007].

Maher P. 1987. Child Abuse: The educational perspective. Oxford: Blackwell.

Malkin K, Johnston LH, Brackenridge CH. 2000. A critical evaluation 
of training needs for child protection in UK sport, Managing Leisure-An International Journal 5: 151-160.

Mason V. 1995. Young People and Sport in England. London: Sports Council. Miles MB, Huberman AM. 1994. Qualitative Data Analysis. $2^{\text {nd }}$ ed. Sage: London.

Reder P, Duncan S. 2004. Making the most of the Victoria Climbié Inquiry Report. Child Abuse Review 13: 95-114. DOI: 10.1002/car.834

Rossato C. 2007. Child protection/safeguarding training in sports-related degrees and initial teacher training: A study of provision in institutions of higher education. Unpublished MSc dissertation, Brunel University, UK.

Sport England. 2004. PE, School Sport and Club Links Strategy. Sport England: London. Available: http://www.sportengland.org/pesscl.htm [31 March 2008].

TDA (Training and Development Agency for Schools). 2007. Professional Standards for Teachers: Why sit still in your career? TDA: London. Available: http://www.tda.gov.uk/upload/resources/pdf/s/standards_a4.pdf [8 August 2007].

Tomlinson A, Yorganci I. 1997. Male coach/female athlete relations: gender and power relations in competitive sport. Journal of Sport and Social Issues 21(2): 134-155. 